\title{
MYRINGOTOMY FOR THE TREATMENT OF OTITIS MEDIA WITH EFFUSION; A COMPARISON IN THE OUTCOME WITH AND WITHOUT GROMMET INSERTION
}

\author{
Sunarays Akhtar, Uzma Gul*, Arfat Jawaid*, Khalid Azam*, Muhammad Sohail Babur Niazi**, Atif Najam*** \\ PAF Hospital, Lahore Pakistan, ${ }^{*}$ Combined Military Hospital Lahore/National University of Medical Sciences (NUMS) Pakistan, ${ }^{* *}$ Combined Military Hospital \\ Peshawar/National University of Medical Sciences (NUMS) Pakistan, ${ }^{* * *}$ Combined Military Hospital Kharian/ \\ National University of Medical Sciences (NUMS) Pakistan
}

ABSTRACT

Objective: To compare the outcome of myringotomy with and without grommet insertion in the patients of otitis media with effusion in terms of improvement of hearing in a one-month follow-up.

Study Design: Quasi experimental study.

Place and Duration of Study: Pakistan Airforce Hospital Jacobabad and Combined Military Hospital Lahore Pakistan, from Jan to Dec 2020.

Methodology: A total of 28 patients aged 4-12 years diagnosed to have conductive hearing loss due to otitis media with effusion not responding to medical treatment were included. Non probability convenience sampling was done. Children aged less than 4 years and above 12 years were not included in the study. They were randomly divided into two groups of 14 patients each using lottery method. Group A underwent myringotomy alone whereas group B underwent myringotomy with grommet insertion. Patients in both groups also underwent adenoidectomy on case-to-case basis. Both groups were compared in terms of improvement in hearing post operatively in a one-month follow-up.

Results: There was statistically significant reduction in air bone gap at the end of follow up period as compared to preoperative air bone gap in group B $(p=0.007)$. In group A there was statistically significant reduction in air bone gap at one week $(p=0.002)$ however this improvement was not maintained at 4 weeks $(p=0.386)$.

Conclusion: Myringotomy with grommet insertion had significantly more patients with improved hearing as compared to myringotomy alone after one month.

Keywords: Adenoidectomy, Eustachian tube, Hearing loss conductive, Middle ear ventilation, Otitis Media with effusion.

How to Cite This Article: Akhtar S, Gul U, Jawaid A, Azam K, Niazi MSB, Najam A. Myringotomy for The Treatment of Otitis Media with Effusion; A Comparison in the Outcome with and Without Grommet Insertion. Pak Armed Forces Med J 2021; 71(Suppl-3): S521-525.

Doi: https://doi.org/10.51253/pafmj.v1i1.7920

This is an Open Access article distributed under the terms of the Creative Commons Attribution License (https://creativecommons.org/licenses/by-nc/4.0/), which permits unrestricted use, distribution, and reproduction in any medium, provided the original work is properly cited.

\section{INTRODUCTION}

Otitis media with effusion (OME), is defined as the collection of fluid in the middle ear and sometimes in the mastoid air cell system. The effusion is predominantly composed of the glycoprotein mucin. Most of the times, cultures of fluid show no pathogens. ${ }^{1}$ Usually there are no features ofacute infection. It is a long standing otitis media in which there is no perforation of the tympanic membrane. The nature of the effusion may be mucous or sero-mucous but it is not purulent. ${ }^{2}$ The underlying cause is decreased ventilation of the middle ear due to poor eustachiantube function. There is immaturity of the child's immune system as well as anatomy of the eustachian tube as it is shorter and more horizontally placed as compared to adults. Other contributory factors include upper respiratory tract infections, adenoid hypertrophy, craniofacial abnormalities, allergies, ciliary dysfunction and gastroesophageal reflux. ${ }^{3}$

Most of the times the condition affects both ears.

Correspondence: Dr Sunarays Akhtar, Classified ENT Specialist, Department of ENT, PAF Hospital, Lahore Pakistan
The most common symptoms include impaired hearing causing a delayin the development of speech and language and consequently poor performance in academics. The condition is diagnosed on history, otoscopic examination, tympanogram and pure tone audiometry. Patients diagnosed with OME can be managed medically or surgically. Medical treatment includes topical and oral steroids, antihistamines like cetirizine and nasal decongestant drops. Surgical management options include adenoidectomy alone or combined with myringotomy with or without grommet insertion. ${ }^{4}$

Myringotomy is a surgical procedure on the tympanic membrane in which a small incision is made through its layers. It allows the drainage of the fluid in the middle ear which is pathognomonic of otitis media with effusion. The fluid aspirated from the middle ear is then sent for bacterial or viral cultures. ${ }^{3}$

If myringotomy and aspiration combined with medical measures do not help and the middle ear fluid reaccumulates, a grommet is inserted and left in place for weeks and months till it is extruded spontaneous- 
ly. ${ }^{5}$ Grommets cause ventilation of the middle ear and equalize the air pressure on either side of the tympanic membrane. Various varieties of grommets are used. One of the commonly used type is the Shepard tube which usually extrudes in about 6 months after placement. The grommets are placed under general anaesthesia and may lead to complications like ear discharge, expulsion, tube obstruction and migration into the middle ear cavity. Late complications include a residual perforation and myringosclerosis. ${ }^{6}$ The history of myringotomy dates back to 1649 . After many decades it was re-introduced in the $19^{\text {th }}$ century by Hermann Schwartze. As the tympanic membrane heals spontaneously efforts were made to keep the perforation patent. One of the first grommets was made of gold. Other substances like rubber were also used however the vinyl tube brought the grommets into the modern day practice. ${ }^{7}$

In this study, we have compared myringotomy alone and myringotomy with grommet insertion in patients having OME in terms of improvement in hearing.

\section{METHODOLOGY}

This quasi experimental study was conducted at the department of ENT, Pakistan Airforce Hospital Jacobabad and Combined Military Hospital Lahore, from January to December 2020. The study population included 28 patients aged 4-12 years diagnosed to have conductive hearing loss due to otitis media with effusion not improving with medical treatment. Non probability convenience sampling was done. Sample size was calculated using WHO sample size calculator using $95 \%$ confidence level and keeping margin of error at $5 \%$.

Inclusion Criteria: Clinically diagnosedcases of otitis media with effusion not improving with medical treatment for at least 3 months.

Patients having "B" type curve on tympanometry. Patients having conductive hearing loss (air bone gap of $>15 \mathrm{~dB}$ ) on Pure Tone Audiometry.

Exclusion Criteria: Children aged less than 4 years and above 12 years.

Children not given a medical treatment trial. Patients having coagulopathies, anemia and other systemic disorders. Patients with craniofacial abnormalities. Patients having preexisting sensorineural hearing loss.

Patients were randomly divided into two groups of 14 patients each using lottery method. Group A was planned to undergo myringotomy alone whereas group B was to undergo myringotomy with grommet insertion. Additionally patients in both groups were also to undergo adenoidectomy on case to case basis. Both groups were to be compared in terms of improvement in hearingpost operatively in a followup period of four weeks.

A thorough history from the parents was taken and a complete ENT examination was performed in all patients including the tuning fork tests. This was followed by otoscopy and tympanometry. Audiometry with bone conduction was done in all patients. Presence of hypertrophied adenoids was diagnosed on plain radiograph of neck lateral view. The parents were counselled regarding the procedures in both groups and a written informed consent was obtained in each case.

The hospital ethics committee's approval for the study was obtained. Preoperative investigations including complete blood picture, coagulation profile, hepatitis serology and covid screening were performed. Each patient was made nil per oral a night prior to the surgery. All the procedures were done under general anaesthesia. Peroperatively using the operating microscope, myringotomy with suction of the middle ear fluid was done in group A where as in group B the patients underwent myringotomy and grommet insertion. Adenoidectomy was done in children diagnosed to have its hypertrophy in both groups (13 cases in group A and 12 in group B). Postoperatively the patients were given oral amoxicillin, chlorpheneramine, xylometazoline nasal spray and ibuprofen. The surgeries were performed on day care basis and the patients were discharged once considered stable and fully out of the effects of general anaesthesia. The patients were called for follow up on the $1^{\text {st }}$ and $4^{\text {th }}$ week post-operatively. They were assessed for hearing improvement on history, examination, audiometry and tympanometry on each follow up visit.

Data was entered using SPSS-25 for statistical analysis. Mean \pm SD were calculated for quantitative variables. Qualitative variables were presented in terms of frequencies and percentages. Non parametric tests for related samples were used to compare the air bone gaps within and between the two groups. $p$-value of $\leq 0.05$ was taken to be significant.

\section{RESULTS}

Twenty eight patients were enrolled and divided randomly into two equal groups. Baseline characteristics of the patients are shown in Table-I. 
Group A $(n=14)$ underwent myringotomy alone whereas group $B(n=14)$ underwent myringotomy with grommet insertion. Out of 13 patients in group A and 12 patients in group $\mathrm{B}$ also underwent adenoidectomy $(p=0.541)$.

Pure tone audiometry was performed in all the patients preoperatively and air bone gap was assessed. This was again done at one week and four weeks postoperatively as shown in Table-II.

Table-I: Baseline characteristics of patients.

\begin{tabular}{|c|c|c|}
\hline $\begin{array}{l}\text { Baseline } \\
\text { Characteristics }\end{array}$ & $\begin{array}{c}\text { Group A } \\
(n=14)\end{array}$ & $\begin{array}{c}\text { Group B } \\
(n=14)\end{array}$ \\
\hline \multicolumn{3}{|l|}{ Age } \\
\hline Mean \pm SD (years) & $7.4 \pm 1.8$ & $7.7 \pm 1.7$ \\
\hline \multicolumn{3}{|l|}{ Gender } \\
\hline $\begin{array}{l}\text { Male } \\
\text { Female }\end{array}$ & $\begin{array}{l}8(57.1 \%) \\
6(42.8 \%)\end{array}$ & $\begin{array}{l}9(64.2 \%) \\
5(35.7 \%)\end{array}$ \\
\hline
\end{tabular}

Table-II: Improvement in air bone gap in both groups.

\begin{tabular}{|c|c|c|c|c|c|c|}
\hline & \multicolumn{3}{|c|}{ Group A (n=14) } & \multicolumn{3}{|c|}{ Group B (n=14) } \\
\hline & D & 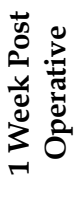 & 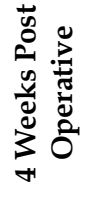 & 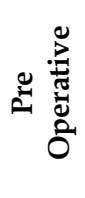 & 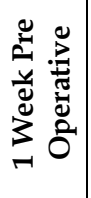 & 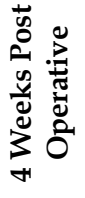 \\
\hline \multicolumn{7}{|c|}{ Air Bone Gap on Pure Tone Audiometry } \\
\hline$<20 \mathrm{db}$ & 3 & 11 & 5 & 2 & 13 & 12 \\
\hline $20-40 \mathrm{db}$ & 11 & 3 & 9 & 12 & 1 & 2 \\
\hline
\end{tabular}

Preoperatively there was no significant difference in the air bone gap between the two groups $(p=0.50)$. In group A the air bone gap reduced significantly $(p=$ 0.002 ) at week 1 as compared to the preoperative values. However at 4 weeks followup the air bone gap in group A again increased so that the difference between the preoperative findings and 4 weeks was not statistically significant $(p=0.386)$ as shown in Figure-1.

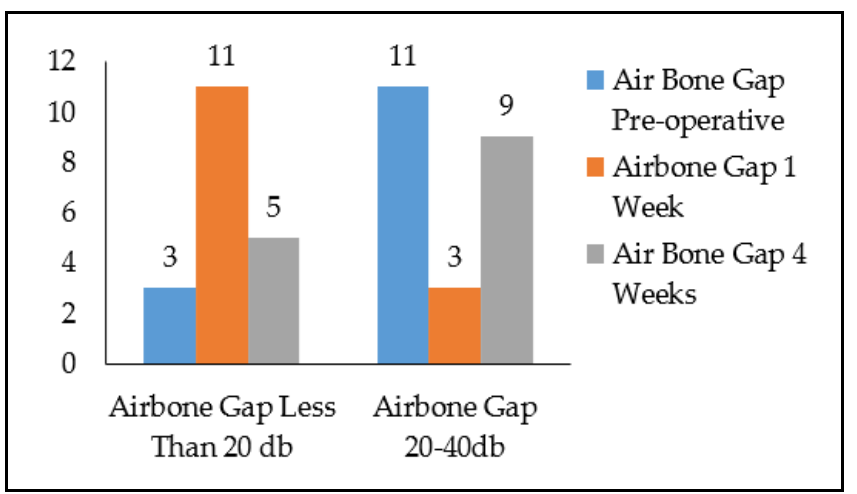

Figure-1: Comparison of air bone gaps in Group A.

In group $B$ there was statistically significant reduction $(p=0.002)$ in the air bone gap at 1 week. This improvement was maintained at the 4 weeks follow up so that at 4 weeks there was statistically significant difference from the preoperative levels $(p=0.007)$ as shown in figure 2 and Table-III.

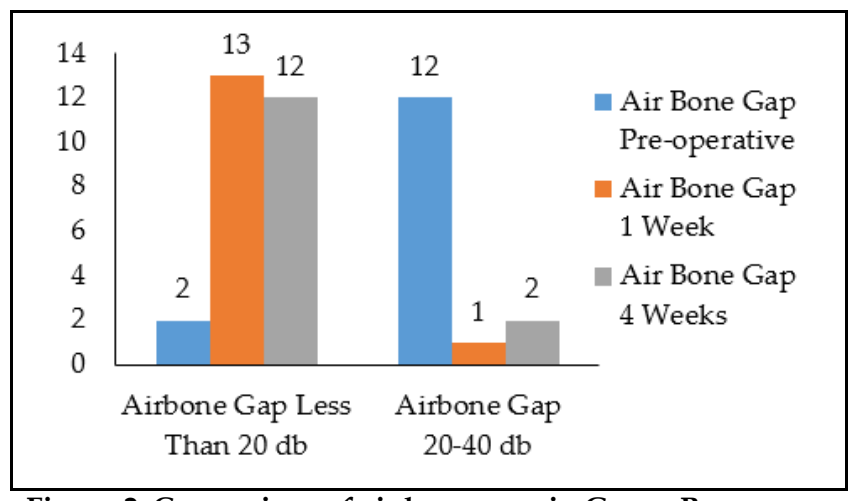

Figure-2: Comparison of air bone gaps in Group B.

Table-III: Pairwise comparison of airbone gap improvement within both groups.

\begin{tabular}{l|c|c}
\hline & $\begin{array}{c}\text { Group A } \\
(\boldsymbol{p} \text {-value })\end{array}$ & $\begin{array}{c}\text { Group B } \\
(\boldsymbol{p} \text {-value })\end{array}$ \\
\hline Preoperative versus 1 week & 0.002 & 0.002 \\
\hline One week versus 4 weeks & 0.028 & 1.000 \\
\hline Preoperative versus 4 weeks & 0.386 & 0.007 \\
\hline \multicolumn{2}{l|}{ (Related samples Cochrane $Q$ test used as the test of significance. $p$ - } \\
value $\leq 0.05$ taken as statistically significant)
\end{tabular}

\section{DISCUSSION}

Otitis media with effusion is acommon condition in the pediatric age group. It is described as the collection of middle ear fluid without the clinical features of an acute infection. It is a disease of childhood and $90 \%$ children suffer from at least one episode before they are 10 years old. Children with craniofacial abnormalities and adenoid hypertrophy are at a higher risk. Hearing impairment in children with preexisting sensorineural hearing loss is augmented due to asuperimposed conductive hearing loss when they develop otitis media with effusion. Most episodes of otitis media with effusion resolve spontaneously in 12-16 weeks but $30-40 \%$ recur. Diagnosis is based upon clinical examination, tympanometry (type B curve) and an air bone gap of $25 \mathrm{dBor} 10 \mathrm{~dB}$ above the normal hearing threshold. ${ }^{8}$ Healthy childrenhaving otitis media with effusion shouldinitially be observed for up to 3-6 months for spontaneous recovery (resolution of the effusion) before embarking on surgery however children at increased risk, like those with craniofacial abnormalities should be offered prompt surgical intervention. ${ }^{9}$

In the present study only those patients were included who had persistent Otitis media with effusion despite observation and medical treatment. Surgical options were offered on case to case basis and myrin- 
gotomy with and without grommet insertion was performed. It was observed that although myringotomy and aspiration of middle ear fluid along with adenoidectomy where needed, resulted in improvement in hearing levels in the 1st week of postoperative followup however there were more cases of recurrence on the $4^{\text {th }}$ week of follow up in this group as compared to those who underwent myringotomy along with grommet insertion. These results are comparable to the study by Siegel et al, who recommended that though myringotomy may be useful in certain conditions, it is not of much benefit alone in children with chronic otitis media with effusion, in which case a grommet should be placed. ${ }^{9}$

As per Scott-Brown's text book of otolaryngology, myringotomy with suction of middle ear fluid but without placement of a ventilation tube is an ineffective management of otitis media with effusion. ${ }^{10}$ In a similar study by Jefferson et al, it was stated that grommet insertion is one of the most commonly performed surgery worldwide as it facilitates drainage of middle ear fluid and allows direct administration ofototopic drugs, however is related to risk of general anaesthesia, early or late tube extrusion, perforation, chronic otorrhea, tympanosclerosis and acquired cholesteatoma so the decision should be made as per the clinicalpicture with long term followup and hence its use remains debatable. ${ }^{11}$ In thepresent study grommets were only used in patients not responding to medical treatment and with chronic otitis media with effusion (persisting for three months or longer) and showed lower recurrence rates with better hearing over a one month follow up as compared to those in which they were not inserted. In a study by Cayé-Thomasen et al, it was concluded that the insertion of grommets after myringotomy provides better hearing until extrusion but is associated with long term complications. The improvement in hearing may also positively affectspeech and language development. ${ }^{12}$

In this study the long term effects of grommets have not been studied however studies by Ragab et al, and Browning et al, concluded that grommet insertion is a temporary procedure until the Eustachian tube function returns to normal however it has many associated problems during and after insertion. ${ }^{13,14}$ In a study by Chaudhuri et al, medical treatment was compared with adenoidectomy, myringotomy and grommet insertion and they concluded that myringotomy with grommet insertion with or without adenoidectomy was a reliable management optionfor otitis media with effusion as it gave a $92 \%$ cure rate as compared to $60 \%$ cure rate for the medical treatment. 15 This is in contrast to a study by Lous et al, in which the authors concluded that as the potential adverse effects of grommets are common, an initial period of observation is more justified. ${ }^{16}$ Bandyopadhyay et al, suggested that despite thecurrent literature favoring tympanostomy tube insertion in otitis mediawith effusion, this treatment is associated with complications and further research is needed to assess the risk benefit ratio. ${ }^{17}$ Similarly OuthoffKalso pointed out that there is relatively strong evidence that grommet insertion in children with chronic otitis media with effusion is associated with complications and should only be used on case to case basis. ${ }^{18}$ As in similarity to the present study Wallace et al, concluded that Myringotomy with grommet insertion and adenoidectomy reduce time with otitis media with effusion and improve hearing in the short term. ${ }^{19}$ Khan et al, in their study mentioned that patients having otitis media with effusion and those who do not respond to medical treatment for more than 3 months should be considered for myringotomy with grommet insertion at an early stage for improvement in hearing levels and speech development as it is a superior surgical treatment than myringotomy alone. ${ }^{20}$

In this study also we observed that grommet insertion in children with chronic otitis media with effusion with or without adenoidectomy was superior to myringotomy alone as the number of patients having improved hearing after the one month follow up was significantly higher in the group who had grommet insertion in addition to myringotomy.

\section{CONCLUSION}

Myringotomy followed by grommet insertion had significantly more patients with improved hearing (in patients of otitis media with effusion) as compared with myringotomy alone (with or without adenoidectomy) after one month.

\section{Conflict of Interest: None.}

\section{Authors' Contribution}

SA: Data conceptulaization, data collection, UG: Statistical analysis, writing, AJ: Data collection and writing, KA: Proof reading, MSBN: writing and proof reading, AN: Statstical analysis

\section{REFERENCES}

1. Robb PJ, Williamson I. Otitis media with effusion. In: Watkinson JC, Clarke RW(eds). Scott-Brown's Otorhinolaryngology: Head and Neck Surgery. 8th edition. Boca Raton: CRC Press 2018, Available at: https://www.taylorfrancis.com/chapters/edit/ 10.1201/9780203731017-13/otitis-media-effusion-peter-robb-ianwilliamson 


\section{Treatment of Otitis Media}

2. Vanneste P, Page C. Otitis media with effusion in children: pathophysiology, diagnosis, and treatment. a review. J Otol 2019; 14(2): 33-39.

3. Reilly BK. Myringotomy technique. Medscape drugs and diseases. updated Jan 06, 2016, [Internet] Available at: https:// emedicine. medscape.com/article/1890977-technique.

4. Upadhya I, Datar J. Treatment options in otitis media with effusion. Ind J Otolaryngol Head Neck Surg 2014; 66(Suppl-1): 191197.

5. Dhingra PL, Dhingra S. Diseases of ear, nose and throat. 5th edition. Elsev 2010, Available at: https://www.amazon.com/ Diseases-EAR-NOSE-THROAT-Dhingra/dp/8131223647

6. Zernotti ME, Pawankar R, Ansotegui I, Badellino H, Croce JS, Hossny E, et al. Otitis media with effusion and atopy: is there a causal relationship.? World Allergy Organ J 2017; 10(1): 37-40.

7. Rimmer J, Giddings CE, Weir N. The History of Myringotomy and Grommets. Ear Nose Throat J 2020; 99(Suppl-1): 2S-7S.

8. Chavan SS, Nagpure PS. Comparative assessment of grommets with topical intranasal steroid in cases of otitis media with effusion. Ind J Otol 2017; 23(3): 146-150.

9. Siegel B, Chi DH. Contemporary guidelines for tympanostomy tube placement. Curr Treat Options Peds 2015; 1(1): 234-241.

10. Robb PJ, Williamson I. Otitis media with effusion. In: Watkinson JC, Clarke RW (eds). Scott-Brown's Otorhinolaryngology: Head and Neck Surgery. 8th edition. Boca Raton: CRC Press; 2018, Available at: https://www.routledge.com/Scott-Browns-Otorhinolaryngology-and-Head-and-Neck-Surgery-Volume-2Paediatrics/Watkinson-Clarke/p/book/9781138094635

11. Jefferson ND, Hunter LL. Contemporary guidelines for tympanostomy tube placement. Curr Treat Options Peds 2016; 2(2): 224-235.
12. Cayé-Thomasen P, Stangerup SE, Jørgensen G, Drozdziewic D. Myringotomy versus ventilation tubes in secretory otitis media: eardrum pathology, hearing, and eustachian tube function 25 years after treatment. Otol Neurotol 2008; 29(5): 649-657.

13. Ragab A, Mohammed AA, Abdel-Fattah AA, Afifi AM. Prevalence of complications associated with tympanostomy tube insertion. Menoufia Med J 2015; 28(2): 918-922.

14. Browning GG, Rovers MM, Williamson I, Lous J, Burton MJ. Grommets (ventilation tubes) for hearing loss associated with otitis media with effusion in children. Cochrane Database Syst Rev 2010; 10(1): CD001801.

15. Chaudhuri GR, Bandyopadhyay SN, Basu SK. Role of grommet in otitis media with effusion: A necessity or nuisance? A comparative study. Ind J Otolaryngol Head Neck Surg 2006; 58(3): 271273.

16. Lous J, Burton MJ, Felding JU, Ovesen T, Rovers MM, Williamson I. Grommets (ventilation tubes) for hearing loss associated with otitis media with effusion in children. Cochrane Database Syst Rev 2005; 10(1): CD001801.

17. Bandyopadhyay T, Raman EV. Otitis media with effusion (OME) in urban pediatric population in a tertiary care centre: a clinical study. Indian J Otolaryngol Head Neck Surg 2018; 70(2): 267-272.

18. Outhoff K. Grommets-an update on common indications for tympanostomy tube placement. S Afr Fam Pract 2017; 59(3): 13-16.

19. Wallace IF, Berkman ND, Lohr KN, Harrison MF, Kimple AJ, Steiner MJ. Surgical treatments for otitis media with effusion: a systematic review. Pediatr 2014; 133(2): 296-311.

20. Khan MA, Alamgir A, Musharaf M. Comparison of outcome of myringotomy alone with myringotomy and tympanostomy tube (Grommet) in otitis media with effusion (OME). J Rawalpindi Med Coll 2018; 22(1): 140-143. 